\title{
A CONTRADIÇÃO FUNDAMENTAL ENTRE A LÓGICA-VALOR DO CAPITAL [ASSIM COMO DA RIQUEZA ADVINDA DO TRABALHO HUMANO] E A TERRA ${ }^{12}$
}

Wolfdietrich Schmied-Kowarzik ${ }^{3}$

\begin{abstract}
Resumo:
Platão e Aristóteles já haviam detectado uma contradição fundamental entre a oikonomia e a crematística: uma sendo geradora de bem-viver e outra preocupada exclusivamente com o acúmulo de dinheiro. Também Hegel, à sua maneira, demonstrou que, tendencialmente, a sociedade moderna se contrapõe à vida humana e à natureza. Mas foi Marx o primeiro a demonstrar como a lógica do valor, própria da dinâmica produtiva capitalista, instrumentaliza e tende a destruir tanto os seres humanos quanto a natureza. Interessada unicamente na produção de mais-valia, a dinâmica capitalista não se importa em deixar para trás escombros de destruição ambiental e crescente pobreza humana. A lógica da valorização do valor, estaria, portanto, na base de nossa relação alienada com a natureza. A superação dessa tendência implicaria uma transformação revolucionária da própria estrutura da sociedade capitalista, a partir de uma práxis sustentada pela aliança entre as vítimas humanas desse processo no contexto de uma reconciliação com a natureza. (Resumo elaborado pelo tradutor).
\end{abstract}

Palavras-chave: Crematística. Lógica do valor. Natureza. Oikonomia. Lógica do valor. Transformação revolucionária.

\section{THE MAIN CONTRADICTION BETWEEN THE LOGIC-VALUE OF CAPITAL [AS WELL AS THE WEALTH ORIGINATED FROM HUMAN LABOR] AND THE EARTH}

\begin{abstract}
:
Plato and Aristotle had already detected a fundamental contradiction between oikonomia and chrematistics: one being a generator of well-being and the other concerned exclusively with money accumulation. Hegel, in his own way, also demonstrated that modern society tends to oppose itself to human life and nature. But Marx was the first to demonstrate how the logic of value, characteristic of capitalist productive dynamics, instrumentalizes and tends to destroy both human beings and nature. Interested only in the production of surplus value, the capitalist dynamic does not care to leave behind rubble of environmental destruction and increasing human poverty. The logic of valorization of value, therefore, would be at the basis of our alienated relationship with nature. Overcoming this tendency would imply a revolutionary transformation of the very structure of capitalist society, based on a praxis supported by the alliance between the human victims of this process into the context of a reconciliation with nature (Abstract drawn up by the translator).
\end{abstract}

1 Título original: Der Grundwidespruch zwischen der Wertlogik des Kapitals sowie dem Reichtum aus der menschlichen Arbeit und der Erde. Palestra proferida em 2006 num evento em Nürnberg e publicado pela primeira vez em (Müller, 2007) e republicado como capítulo final em (Immler, Hans; SchmiedKowarzik, 2011).

2 Rosalvo Schütz traduziu este artigo. Schütz é professor de Filosofia da Universidade Estadual do Oeste do Paraná (UNIOESTE) e bolsista de produtividade do CNPq.

3 Professor emérito de Filosofia da Universidade de Kassel (Alemanha), atualmente residente em Viena/Áustria. Vários trabalhos seus foram traduzidos no Brasil, sendo um dos mais recentes o livro A relação dialética do homem com a natureza. Estudos histórico-filosóficos sobre o problema da natureza em Karl Marx, pela EDUNIOESTE. Atualmente vem lançando diversos estudos especialmente sobre questões ambientais e filosofia intercultural.

\begin{tabular}{|l|l|l|l|l|}
\hline Q Rovista Dialectus & Ano 10 & n. 21 & Janeiro - Abril 2021 & p. 390 - 403 \\
\hline
\end{tabular}


Keywords: Chrematistics. Logic of value. Nature. Oikonomia. Revolutionary transformation. I.

No primeiro livro de sua Política, Aristóteles diferencia oikonomia e crematística. A oikonomia, como administração da casa, ou melhor, como administração dos bens, tinha em vista a preservação dos bens, de toda a organização dos bens, como sendo a base para a autonomia política dos senhores, os nobres cidadãos de uma Pólis. Mas, evidentemente, também objetivava o bem-estar de todas as pessoas incluídas nesse bem: mulheres, crianças, administradores, camponeses e serviçais. Para tanto, se necessitava de um florescente intercâmbio e produção de bens (Gutswirtschaft), da agricultura (Landwirtschaft) e da criação de animais. O abastecimento daí decorrente não se restringia ao objetivo de propiciar o bem-estar da geração presente, mas se estendia também para a próxima geração: tanto para o filho, como novo senhor dos bens, e os demais filhos, quanto para as filhas e com quem viessem a se casar. Daí que a sustentabilidade da economia (des Wirtschaftens) e a solidariedade familiar junto às famílias "cunhadas" ser uma perspectiva evidente para a oikonomia (Cf. Aristóteles, 2019, p. 1253b-1255b).

Em contraposição a isso, está a crematística, a economia da aquisição de dinheiro (Gelderwerbswirtschaft), a qual, desde sua introdução há aproximadamente 400 anos antes de Aristóteles, sempre de novo e de forma cada vez mais radical, ameaçava a solidez básica e comunitária da Pólis grega e, com isso, a segurança da oikonomia. Ademais, a crematística não está, como a oikonomia, relacionada com a preservação sustentável dos bens e com o bem-estar das pessoas inclusas nesse bem, pois sua lógica objetiva exclusivamente o aumento da quantidade de dinheiro. Portanto, um processo infinito de acumulação que rompe com todos os objetivos solidários e sustentáveis, opondo-se aos mesmos, dilacerando e destruindo-os.

Para a arte de ganhar dinheiro[...] parece que não existe nenhum limite de riqueza e
aquisição. [...] Mas a arte de administrar a família (oikonomia), que, por sua
vez, não é a arte de ganhar dinheiro (crematística), tem um limite; por isso,
parece que existe a necessidade de um limite para toda a riqueza. Mas, na
realidade, vemos acontecer o contrário disso: todos os que praticam a arte de
ganhar dinheiro aumenta infinitamente o seu montante em moeda (Aristóteles,
1973, cotejado com Aristóteles, 2019, p. 1257a-b).

Daí Aristóteles conjecturar sobre meios pelos quais a política possa limitar e domar a crematística. Disso decorre, por um lado, que aos comerciantes e compradores, 
enquanto portadores da economia do dinheiro, não lhes seja permitido serem cidadãos da Pólis, motivo por que enquanto tais eles permaneciam excluídos. Apenas aos proprietários que tinham conseguido permanecer afastados por dez anos dos negócios comerciais lhes era permitido ser admitidos na Pólis como novos cidadãos politicamente livres (Aristóteles, 1999, p. 1329 a-b). Além disso, a Pólis precisava se dar o direito de, por meio de indenização, desapropriar todos os comerciantes e negociantes que tivessem se tornado demasiadamente poderosos por meio da acumulação de dinheiro - como, por exemplo, quando alcançavam um monopólio, ameaçador de toda a Pólis, sobre a produção de ouro e prata. Ou seja, com isso a Pólis podia e devia passar novamente o direito de mineração para um número maior de interessados, pois - e isso é algo muito importante para Aristóteles, em contraposição ao seu mestre Platão, - é preciso assegurar o princípio da livre iniciativa, uma vez que, para Aristóteles, o interesse privado é um motor essencial dos fundamentos econômicos de uma Pólis florescente e em expansão (Cf. Aristóteles, 2009, p. 1263a).

Assim, nós chegamos ao ponto a partir do qual a crítica mais radical da economia empreendida por Platão - o professor de Aristóteles - pode ser focada. Para Platão, conforme expõe na Politeia, não poderia haver uma Pólis justa enquanto os interesses privados, que dominavam as Polis da época, persistissem. Sejam esses interesses motivadas pela acumulação infinita de dinheiro da crematística, ou pelas sucessivas heranças familiares da oikonomia, ou dos egoísmos individualizados de democracia ou mesmo dos interesses de poder de tiranos individuais (cf. Platão, 1971, p. 589a-592b). A partir disso, Platão visualiza, na transformação revolucionária radical, na metabolê, o meio pelo qual o princípio da justiça possa conseguir conquistar uma sobreposição em relação aos interesses econômicos privados: a única esperança utópicoconcreta para a comunidade política e para a própria humanidade. Antes de os filósofos, ou seja, os homens e mulheres éticos, tomarem os rumos políticos da Pólis em suas próprias mãos desde o princípio da justiça, "não haverá recuperação do mal para os Estados [...], e eu penso que nem mesmo para a espécie humana" (Platão, p. 473 b-e).

II.

Façamos um salto para além de dois mil anos. Aqui encontramos novamente as mesmas questões em Hegel e Marx; no entanto, a partir dos problemas políticoeconômicos decorrentes das progressões históricas e numa diferenciação dialética. 
Em sua Filosofia do Direito - e em recorrência a Adam Smith -, Hegel busca se apropriar do problema da relação entre economia e política mediante uma dialética estrutural:

Sobre a base da eticidade originária da família - cujas relações entre homem e mulher e entre pais e filhos representam o fundamento e o centro renovador de toda a eticidade - se sobrepõe à eticidade fundamentalmente dilacerada da economia de aquisição (Erwerbswirtschaft), a economia política da sociedade burguesa. Aqui cada um está autorreferido à sua própria subsistência e em concorrência com todo e qualquer outro. De todo modo, no entanto, por detrás das costas desse empresário e mesmo do trabalhador individualmente ativo, afirma-se a generalidade abstrata do mercado, a necessidade e a violência da dependência de todos em relação a todos. "Na sua realização condicionada desse modo pela universalidade, o fim egoísta é a base de um sistema de dependências recíprocas no qual a subsistência, o bem-estar e a existência jurídica do indivíduo [...] somente são reais e assegurados nessa dependência" (Hegel, 1997, p. 169 [\&183]).

Decisivo, entretanto, é que a concorrência individual - juntamente com as cegas leis do mercado - conduzem necessária e inevitavelmente a contradições recorrentes e cada vez mais fortes. E isso geralmente acontece justamente lá onde a sociedade burguesa, ou seja, a economia de mercado e de aquisição, se encontra no mais florescente progresso de crescimento. Mesmo aí ela não é rica o suficiente para estancar a pobreza e o desemprego por ela mesma causados: "Desse modo se mostra que, apesar de seu excesso de riqueza, não é a sociedade civil suficientemente rica, isto é: na sua riqueza, não possui a sociedade civil bens suficientes para pagar o tributo ao excesso de miséria e à sua consequente plebe" (Hegel, 1997, p. 199 [\&245]).

Daí decorre que esse dilaceramento (Zerrissenheit) da economia de mercado burguesa, que tem por base uma contradição imanente, permaneça insuperavelmente assim. Somente nos casos mais graves, de injustiça gritante e de degradação existencial, pode ser empreendido algo contra. E isso pode ser feito tanto por parte do Estado, por meio de um planejamento prévio da política econômica e da criação de estruturas sociais de uma economia de mercado social, quanto também por parte dos trabalhadores e empresários, pela criação de organizações de autoajuda como, por exemplo, as representações de interesses e seguros de pensão.

Justamente pelo fato de que o dilaceramento da esfera econômica nunca pode ser superado, torna-se necessário, segundo Hegel, a eticidade estruturalmente

\begin{tabular}{|l|l|l|l|l|}
\hline Qovista Dialectus & Ano 10 & n. 21 & Janeiro - Abril 2021 & p. $390-403$ \\
\hline
\end{tabular}


pacificadora do Estado, cuja tarefa política consiste em contribuir de forma sustentável para o bem-estar do indivíduo e da generalidade do conjunto do Estado. O Estado moderno, ou seja, o Estado pós-revolucionário, se funda no reconhecimento do princípio da liberdade política e da igualdade de cada cidadão e pode, por isso, esperar ser reconhecido pelo cidadão individual - seja rico ou pobre - como sendo uma unidade de ação comum (gemeinsame Handlungseinheit). "O princípio dos Estados modernos tem esta imensa força e profundidade: permite que o sujeito da subjetividade alcance a extrema autonomia da particularidade pessoal ao mesmo tempo que reconduz à unidade substancial, mantendo assim esta unidade no seu próprio princípio" (Hegel, 1997, p. 213 $[\& 260])$.

Hegel, que em toda a sua filosofia do "espírito objetivo", da convivência social, não pensa desde os sujeitos humanos, mas das instituições objetivadas, vê no Estado o mais alto sujeito da ação coletiva, para além do qual não se pode ir. A cada Estado, porém, estão contrapostos outros Estados enquanto sujeitos de ação política, com os quais cada um se encontra, inevitavelmente, num permanente 'estado de natureza' e de guerra de todos contra todos - como Hegel, de forma polêmica, se posiciona contra a Ideia da paz perpétua, de Kant. Daí que, em consonância com a dialética estrutural, seja necessária uma estrutura de pacificação ainda mais elevada, a qual Hegel vislumbra no “espírito mundial” (Weltgeist) da história. O 'espírito mundial' revela-se um 'tribunal mundial' (Weltgericht) tanto no que diz respeito ao surgimento e desaparecimento de povos quanto à contribuição de povos e Estados rumo ao tornar-se conscientes, livre e espiritualmente. Mesmo que a história mundial não seja um sujeito de ação política e nem mesmo os Estados individuais e as federações de Estados possam estruturar intencionalmente a história, ainda assim, a história mundial, enquanto tribunal mundial, realiza-se neles e para além deles, pois "a história universal é o progresso na consciência da liberdade - um progresso cuja necessidade temos de reconhecer" (Hegel, 2008, p. 25).

III.

É justamente aqui que incide a crítica de Marx a Hegel, realizada nos Manuscritos econômico-filosóficos. Segundo Marx, o espírito mundial não é o sujeito da história, esse sujeito são os seres humanos que, por meio de seu trabalho e de sua práxis, se vinculam uns com os outros e, por sua vez, também estão vinculados e inseridos na produtividade da natureza (Marx, 2008, p. 126). Sua liberdade, ainda a ser efetivada, é o 
objetivo da história. E para essa emancipação humana, sua autolibertação, os seres humanos haverão de lutar contra as adversidades que lhes estão contrapostas.

Acima de tudo e, primeiramente, Marx converte a dialética estrutural de Hegel em uma dialética histórica. O dilaceramento da esfera econômica, a qual Hegel analisa tão acertadamente, não é um dilaceramento da capacidade de aquisição humana, mas ela é - segundo Marx - o dilaceramento, a alienação, e a inversão do modo de produção da atualidade, o modo capitalista de produção, historicamente surgido. Por isso ele pode ser historicamente superado, e isso principalmente porque na base vital e social humana está socialmente contido um potencial de produção não alienado dos indivíduos, na forma de preservação e regeneração natural da vida e da sociedade. Também o modo de produção capitalista precisa estar atento à manutenção da vida dos seres humanos trabalhadores, tanto no que diz respeito ao seu intercâmbio material com a natureza, quanto de sua renovação e regeneração social. Mas na inversão/erro (Verkehrtheit) do trabalho alienado cada trabalhador é forçado a se voltar sobre si mesmo e, assim, é alienado/estranhado tanto da sociedade quanto da natureza:

O trabalho estranhado faz, por conseguinte: 3) Do ser genérico do homem, tanto da natureza quando da faculdade genérica espiritual dele, um ser estranho a ele, um meio de sua existência individual. Estranha o homem do seu próprio corpo, assim como a natureza fora dele, tal como a sua essência espiritual, a sua essência humana (Marx, 2008, p. 85).

Apenas onde os seres humanos trabalhadores se tornam conscientes de sua alienação, eles podem, numa práxis revolucionária, transformar as relações alienadas e se tornar capazes de estruturar solidariamente a sua convivência social e ecológica (sua relação de preservação de vida no intercâmbio material com a natureza). É diante dessa tarefa prático-histórica que, segundo Marx, nós estamos colocados. A eticidade pacificada, cuja realização estrutural Hegel já via no Estado moderno, precisa, segundo Marx, primeiramente ser conquistada por uma transformação revolucionária do modo de produção capitalista.

Na época presente, o domínio das relações materiais [sachlichen Verhältnisse] sobre os indivíduos, o esmagamento das individualidades pela causalidade, atingiu sua forma mais aguda e universal e, com isso, designou aos indivíduos existentes uma missão bem determinada. Ela deu aos indivíduos a missão de, no lugar do domínio das relações dadas e da causalidade sobre os indivíduos,

\begin{tabular}{|l|l|l|l|l|}
\hline Q Povista Dialectus & Ano 10 & n. 21 & Janeiro - Abril 2021 & p. 390 - 403 \\
\hline
\end{tabular}


instaurar a dominação dos indivíduos sobre a causalidade, e sobre as relações dadas (Marx, 2007, p. 422 ) 4.

IV.

Os contornos dessa dialética histórica Marx já desenvolve nos Manuscritos econômico-filosóficos para a crítica da economia política, de 1844, e eles constituem a base de todos os seus trabalhos posteriores, mas, a partir de 1854, com o início de seu projeto mais amplo de uma Crítica da economia política, Marx modifica a estratégia de sua análise. A fim de deixar claro aos seres humanos trabalhadores a necessidade irrefutável de uma transformação revolucionária do modo de produção capitalista, ele confronta a lógica negativa do capitalismo com o espelho da teoria negativa dela, evidenciando, de modo imanente, que a lógica do valor, posta como absoluta, é o fundamento de toda riqueza social: é a lógica do valor posta de modo absoluto (absolutgesetzte Wehrtlogik), que arruína tanto o trabalho quanto a terra, uma vez que explora os trabalhadores onde os precisa e os descarta onde não mais os precisa, do mesmo modo que saqueia a natureza onde pode extrair alguma utilidade da mesma e a abandona destruída e envenenada onde ela se lhe torna inútil.

\footnotetext{
Antecipação do futuro - antecipação real - [no sentido de prescrição] só ocorre em geral na produção da riqueza no tocante ao trabalhador e à terra. Em ambos, o futuro pode ser na realidade antecipado e devastado por extenuação e esgotamento prematuros, pela perturbação do equilíbrio entre o que recebem e o que dão. É o que sucede com ambos na produção capitalista (Marx, 1985a, p. 1355).
}

Foi a partir de uma intencionalidade crítica, mas completamente erigida sobre a economia clássica, de alguém como Adam Smith e David Ricardo, que Marx desvendou os segredos da lógica capitalista do valor e mostrou como ela extrai toda a sua força da exploração do trabalho [embora busque ocultar isso perante si mesma e perante o mundo], do mesmo modo como ela, incessantemente, pode saquear a natureza, a terra, sem despender ao menos um grão de valor com ela - para obter a força de trabalho: pelo menos o Capital ainda precisa pagar salário, as forças da natureza ele obtém gratuitamente.

A teoria marxiana do valor-trabalho é suficientemente conhecida: Todo o valor advém do trabalho capitalistamente utilizado, onde constantemente é sugado maisvalor do trabalho atraído para o processo de valorização e acumulação do Capital, na

\footnotetext{
4 Sobre esse assunto confira (Schmied-Kowarzik, 1981).
}

\begin{tabular}{|c|c|c|c|c|}
\hline Rovista Dialectus & Ano 10 & n. 21 & Janeiro - Abril 2021 & p. $390-403$ \\
\hline
\end{tabular}


medida em que o salário da força de trabalho equivale a apenas uma fração do valor do trabalho fornecido. Como a lógica do valor esconde esse segredo do crescimento do valor diante de si mesma, a produção de mais-valia aparece como se fosse pura autovalorização do Capital, a qual, uma vez jogada no processo de valorização, lança, de maneira aparentemente inexplicável, seus filhotes.

Algo diferente acontece como a pilhagem das riquezas da terra e sua transformação em valor. Primeiramente, a natureza pode ser obtida em todos os lugares por uma tarifa zero (Nulltarif). Matérias-primas, forças da natureza, processos naturais de crescimento não têm nenhum valor do ponto de vista da economia do valor. Os custos das matérias-primas são constituídos, em primeiro lugar, pelos custos do trabalho de sua extração, transporte, seu cuidado e seu acabamento, assim como, em todos os casos, os custos do trabalho do descarte dos seus restos. Ou seja, inicialmente, nenhuma forma de riqueza da natureza se torna valor enquanto natureza, mas ela apenas é incluída no cálculo do valor na medida em que é transformada em carga de trabalho.

Secundariamente, no entanto, se evidencia que aqui se torna necessário ainda um segundo fator, o qual Marx analisa através da categoria "renda da terra" - um capítulo, que Friedrich Engels incluiu equivocadamente no terceiro volume de $O$ Capital, em vez de lançá-lo como livro próprio, na sequência de $O$ Capital. As formas específicas de matérias-primas dos donos das terras (Grundeigentümer), ou a produtividade específica do solo ou de forças naturais, ou a posse de patentes sobre determinados processos de produção por meio de procedimentos físicos, químicos e, como acontece atualmente, também biológicos, e em decorrência de sua posição privilegiada de monopólio, permitem extrair daí a mais-valia-extra (Surplusprofit), como se fosse uma 'renda da terra'.

\begin{abstract}
A força natural não é a fonte do lucro suplementar (Surplusprofit), mas base natural dele, por ser a base natural da produtividade excepcionalmente acrescida do trabalho. Do mesmo modo, o valor-de-uso não é a causa, mas o suporte do valor de troca. O mesmo valor-de-uso, se puder ser obtido sem trabalho, não terá valor-de-troca [valor], embora mantenha a mesma utilidade natural que o caracteriza (Marx, 1985, p. 741).
\end{abstract}

A forma como o valor de monopólio sobre o solo, sobre as matérias-primas e as forças da natureza pode ser calculado a partir da diferença da renda da terra, não precisa nos interessar aqui.

\begin{tabular}{|l|l|l|l|l|}
\hline Qonista Dialectus & Ano 10 & n. 21 & Janeiro - Abril 2021 & p. 390-403
\end{tabular}


Resumamos rapidamente em uma conclusão provisória: a lógica do valor do Capital tem uma fome voraz (Heisshunger) por trabalho gerador de mais-valia, mas ela é totalmente indiferente em relação aos trabalhadores vivos - ela os descarta do processo de trabalho onde eles não despendem a mais-valia diferencial média socialmente exigida. A natureza, embora o Capital precise muito de suas riquezas e forças para o processo de acumulação, não é incluída enquanto tal no cálculo do valor: ela está à disposição por tarifa zero. Mas é claro que, por outro lado, entram, no cálculo do valor, os custos de trabalho para a extração das matérias-primas, do plantio do solo e do descarte das sobras e, por outro lado, a mais-valia-extra (Surplusprofite) dos monopólios de posse da terra, dos recursos naturais e da posse de patentes sobre processos naturais.

Decisivo é que, nunca e em lugar algum, a lógica do valor do Capital está interessada nas condições de vida dos seres humanos trabalhadores ou nos circuitos ecológicos vitalmente necessários, mas única e exclusivamente na produção de maisvalia, na valorização do valor e na acumulação do valor; portanto, na crematística.

Exatamente da mesma forma que o Capital globalizado expulsa os trabalhadores que não lhe forneçam mais-valia suficiente, ele deixa atrás de si uma natureza saqueada e envenenada, lá onde os custos da mão-de-obra lhes sejam muito altos e a mais-valia-extra muito baixa. De fato, a economia capitalista do valor também tem fome voraz pela totalidade de fontes naturais "desprovidas de valor" (Wehrtlose), mas apenas lá onde estas, quando inseridas no processo de produção, tenham dispendido uma mais-valia extra como vantagem competitiva de monopólio - daí a corrida por patentes, a opção do monopólio pela busca de cultivos geneticamente manipulados, adubos e processos naturais físicos, químicos e biológicos que, por um lado, aumentam a produtividade, mas também, por outro lado, simultaneamente, proporcionam uma maisvalia-extra frente à concorrência.

Ciclos ecológicos naturais não interessam à economia do valor. Fontes naturais são saqueadas enquanto os custos de trabalho para a sua extração não sejam comparativamente muito altos. A economia do valor não se importa com o estado da natureza que 'fica para trás'. O que interessaria à lógica crematística do Capital sobre o que acontece com o espaço de vida de muitos seres humanos e animais, ou que as matas virgens do Brasil se tornem desertos depois de serem desmatadas, ou mesmo que nos campos da Nigéria e do Equador fiquem para trás as manchas de óleo, que regiões em torno de Chernobyl ou na Sibéria, ou do mar gelado em torno de Murmansque, estejam 
contaminadas por séculos e até milhares de anos? Não interessa nem mesmo o clamor que recentemente saiu da Grã-Bretanha e circulou o mundo - de que em consequência das catástrofes climáticas industrialmente geradas também se chegará a um colapso global dos mercados financeiros - bem pior do que em 1929 - por meio da qual não apenas serão liquidados montantes gigantescos de valor de capital, mas também alguns proprietários de capital assim como milhões de seres humanos trabalhadores serão lançados à ruina. Diante de tudo isso a economia de valor permanece indiferente, pois para isso - para as catástrofes humanas de todas as formas por ela geradas - ela não tem nenhum sensor. Em todo caso, especuladores astutos cuidarão para que seus valores de capital sejam resguardados a tempo, a fim de que possam, nas fases posteriores de necessária reconstrução, ser reinvestidos com lucros exorbitantes.

Evidentemente, existem intervenções estatais e movimentos que, assim como Hegel acertadamente mostrou, conseguem interceptar e amenizar os processos mais brutais de empobrecimento dos seres humanos trabalhadores e as piores catástrofes ecológicas. Mas esses movimentos sociais nunca podem - por um lado, por exemplo, o Movimento Sem-Terra no Brasil, as ilhas de produção ecológica, assim como as ações do Greenpeace e, por outro lado, as medidas estatais e de direito em vista da assistência social ou da proteção ao clima - suspender a contradição entre a lógica do valor do Capital e os interesses naturais e sociais dos seres humanos sem romper com a lógica da valorização do valor.

Foi isso que Marx nos quis deixar claro com sua Crítica da economia política, na medida em que expõe de modo imanente a lógica do Capital em sua negatividade por menos de uma transformação revolucionária o autoencontro dos seres humanos como humanos e a reconciliação do ser humano com a natureza não poderá ser obtida (SchmiedKowarzik, 1988).

\section{Teses conclusivas:}

1 - A partir da lógica do valor não se deixa erigir uma sociedade socialista ou uma política ecológico-solidária. A Crítica da economia política, de Marx, não é uma economia crítica, mas a negação da negatividade da economia do valor, na medida em que revela a negação do ser humano e da natureza por meio da economia do valor. Com isso ela objetiva o esclarecimento político dos atingidos, na medida em que deixa claro que, quando se trata de sua libertação, não há caminho que possa contornar uma 
transformação revolucionária da ditadura da lógica do valor, da dominação da crematística (Platão - Marx).

2 - No entanto, apenas a Crítica da economia política, a negação da economia do valor e a crítica da ação destruidora que ela gera não bastam - como achavam alguns representantes da teoria crítica - de modo algum: também precisamos desenvolver e experimentar alternativas. Contudo, para poder pensar e experimentar essas alternativas, não podemos partir da economia do valor, mas precisamos recorrer aos resíduos de resistência (Henri Lefebvre) que se radicam em nossas bases naturais e sociais vitais, para, a partir destas, anteciparmos as alternativas concreto-utópicas (Ernst Bloch). Nesse sentido, eu apoio enfaticamente os esforços de Hans Immler por uma economia ecológico-social5.

3 - A base das alternativas não pode ser procurada e encontrada na economia capitalista do valor, mas unicamente na produção social da vida social, a qual, por sua vez, também está inserida num processo ecológico de intercâmbio material com a produtividade da natureza. Todas as tentativas de pautar a resistência contra o capitalismo apenas a partir da melhoria de vida dos trabalhadores assalariados são insuficientes. A alternativa à economia do valor precisa ser pensada pelo conjunto dos seres humanos trabalhadores, e a estes pertencem todos os que estejam envolvidos na produção e reprodução da vida humana no contexto da produtividade natural.

Eu lembro aqui, exemplarmente, A origem da família, da propriedade privada e do Estado, publicado em 1884, de Friedrich Engels (1975), ou o livro da etnóloga francesa Claude Maillassoux Os frutos selvagens da mulher. Sobre produção doméstica e economia capitalista (1976). Para podermos pensar em alternativas de vida humanas precisam ser incluídos todos os trabalhos que regeneram e renovem a vida social da humanidade e que humanizem sua convivência - justamente aquilo tudo que é destruído, degenerado e orientado para fins estranhos na medida em que é incorporado na globalização da economia do valor.

4 - Da mesma forma, no que diz respeito à problemática da destruição da natureza, não se tratar apenas de tornar mais limpos os processos industriais instituídos e mais avançados. Ou seja, não se trata apenas de forçar as empresas capitalistas, por meio

5 Trata-se da argumentação de Hans Immler, em debate com W. Schmied-Kowarzik, sobre o papel da natureza na constituição do valor-de-troca, desenvolvida a partir da p. 143, em capítulo intitulado "Você responde corretamente, mas a sua pergunta estava falsa". O debate está registrado no livro: (Immler, Hans; Schmied-Kowarzik, Wolfdietrich, 2011). [Nota do tradutor].

\begin{tabular}{|l|l|l|l|l|}
\hline Q & Ano 10 & n. 21 & Janeiro - Abril 2021 & p. 390 - 403 \\
\hline
\end{tabular}


de medidas do direito, a sanar os prejuízos ambientais que elas causaram em sua produção, mas precisamos repensar as relações entre os seres humanos e a natureza de uma forma muito mais fundamental, desde o presente estranhamento, na forma como, até certo ponto, Marx concebeu isso em seus Manuscritos econômico-filosóficos, recorrendo a Schelling6 e Feuerbach.

Também a atual forma de determinação (Formbestimmtheit) da ciência natural e da técnica é alienante e "desumanizante". Em contraposição a isso, se trata de pensar os seres humanos como inseridos na produtividade da natureza e a natureza enquanto momento de humanização. Se a indústria for

[...] apreendida como revelação exotérica das forças essenciais humanas, então também a essência humana da natureza ou essência natural do homem é compreendida dessa forma, e por isso a ciência natural perde a sua orientação abstratamente material, ou antes idealista, tornando-se a base da ciência humana, como agora já se tornou - ainda que em figura estranhada - a base da vida efetivamente humana (Marx, 2010, p. 112).

Então, como afirma Marx, existirá apenas uma ciência e indústria, que abarcará simultaneamente o ser humano e a natureza de modo ecológico e solidário (cf. Marx, 2010, p. 112).

5 - Nem uma sociedade comunista nem uma tecnologia solar - como fantasia Elmar Altvater (2005) - podem, apenas a partir delas mesmas, nos libertar da lógica do valor do Capital. Isso só pode ocorrer por meio de um movimento político-revolucionário, o qual - como formulado pelo jovem Marx - intente a emancipação humana. Com essa perspectiva utópica Marx avançou muito pouco para além de Platão, mas ele nos deixou claro que apenas para acima dessa dialética pode ser possível uma sobrevivência ética da humanidade.

Com esses indicativos, no meu modo de ver, não se trata de advogar a favor de um retorno anterior às conquistas técnico-científicas da atualidade, mas de apontar, desde o trabalho social e sua inserção na produtividade natural, para a base a partir da qual seja possível a crítica às relações injustas e desde onde a perspectiva de sua superação revolucionária deve ser sempre de novo antecipadamente projetada e praticamente tentada.

6 Sobre a crítica de Schelling à coisificação da natureza (Naturverdinglichung) compare (Schelling, 1956) e também (Schmied-Kowarzik, 1996).

\begin{tabular}{|l|l|l|l|l|}
\hline Q & Ano 10 & n. 21 & Janeiro - Abril 2021 & p. 390 - 403 \\
\hline
\end{tabular}


6 - Apenas a partir dos dois juntos: da antecipação concreto-utópica e da crítica às inversões da economia movida pelo valor, o trabalho de esclarecimento dos seres humanos pode conduzir para a responsabilidade histórica de iniciar a superação do capitalismo. Até mesmo para pensar e fazer avançar essa superação nós precisamos de toda a nossa força de antecipação concreto-utópica, pois a superação (Aufhebung) não significa a simples eliminação do dinheiro, do capital, da ciência e da técnica. O que dever ser superado é a negação da negação, ou seja, a ditadura da economia do valor sobre os seres humanos e sobre a natureza. A perspectiva-alvo de toda a práxis políticorevolucionária precisa ser sempre a 'ditadura' de uma produção solidário-ecológica, para além dos instrumentos calculistas (Verrechnungsinstrumente), e em benefício da preservação da natureza fundante da vida e do aumento da qualidade de vida humana (cf. Schmied-Kowarzik, 1999).

A partir do que foi dito, gostaria de concluir com uma citação de Marx extraída do terceiro volume de $O$ Capital:

\begin{abstract}
Quando a sociedade atingir formação econômica superior, a propriedade privada de certos indivíduos sobre parcelas do globo terrestre parecerá tão monstruosa como a propriedade privada de um ser humano sobre outro. Mesmo uma sociedade inteira não é proprietária da terra, nem uma nação, nem todas as sociedades de uma época reunidas. São apenas possuidoras, usufrutuárias dela, e como bonipatres famílias têm de legá-la melhorada às gerações futuras (Marx, 1985, p. 891).
\end{abstract}

\title{
Referências:
}

ALTVATER, Elmar. Das Ende des Kapitalismus wie wir ihn kennen. Eine radikale Kapitalismuskritik. Münster: Verlag Westfälisches Dampfboot, 2005.

ARISTÓTELES. Política. Tradução e notas: Maria Aparecida de Oliveira Silva. São Paulo: Edipro, 2019.

ARISTÓTELES. Politik. Übers. von. Olof Gigon. München: Taschenbuch, 1973.

ENGELS, Friedrich. Der Ursprung de Familie, des Privateigentums und des Staates. In: Marx-Engels-Werke, v. 21. Berlin: Dietz Verlag, 1975.

HEGEL, Friedrich. Princípios da Filosofia do Direito. Coleção fundamentos do Direito. 2. ed. Tradução: Norberto de Paula Lima. São Paulo: Ícone, 1997.

HEGEL, Friedrich. Filosofia da História. Tradução: Maria Rodrigues e Hans Harden. 2. ed. Brasília: Editora Universidade de Brasília, 2008.

\begin{tabular}{|l|l|l|l|l|}
\hline Qovista Dialectus & Ano 10 & n. 21 & Janeiro - Abril 2021 & p. 390-403 \\
\hline
\end{tabular}


IMMLER, Hans; SCHMIED-KOWARZIK, Wolfdietrich. Marx und die Naturfrage. Ein Wissenschaftsstreit um die Kritik de politischen Ökonomie. Kassel: Kassel Universty Press GmbH, 2011.

MARX, Karl. O Capital: crítica da economia política. O processo global de produção capitalista. Livro III. Vol. VI. Tradução: Reginaldo Sant'Anna. São Paulo: Difel, 1985.

MARX, Karl. Teorias da mais-valia. In: O Capital: crítica da economia política. O processo global de produção capitalista. Livro IV., Vol. III. Tradução de Reginaldo Sant'Anna. São Paulo: Difel, 1985a.

MARX, Karl. Manuscritos econômico-filosóficos. Tradução: Jesus Ranieri. São Paulo: Boitempo, 2010.

MARX, Karl. A ideologia alemã. Tradução: Rubens Enderle, Nélio Schneider, Luciano Cavini Montorano. São Paulo: Boitempo, 2007.

MEILLASSOUX, Claude. Die wilden Früchte der Frau. Über häusliche Produktion und kapitalistische Wirtschaft. Frankfurt a. M.: Suhrkamp, 1976.

PLATON. Der Staat. Übers. von. Friedrich Schleiermacher. Darmastadt: Wissenschaftliche Buchgesellschaft, 1971.

SCHELLING, Friedrich.W.J.. Darlegung des wahren Verhältnisses der Naturphilosophie zu der verbesserten Fichteschen Lehre. In: Sämtliche Werke in 14 Bden. Bd. VII, Stuttgart-Augsburg, 1856.

SCHMIED-KOWARZIK, Wolfdietrich. Denken aus geschichtlicher Verantwortung. Wegbahnungen zur praktischen Philosophie. Würzburg, 1999.

SCHMIED-KOWARZIK, Wolfdietrich. Die Dialektik der gesellschaftlichen Práxis. Zur Genesis und Kernstruktur der Marschen Theorie. Freiburg/München, 1981.

SCHMIED-KOWARZIK, Wolfdietrich. "Von der wirklichen, von der seyenden Natur". Schellings Ringen um eine Naturphilosophie in Auseinandersetzung mti Kant, Fichte und Hegel. Stutgard-Bad, 1996. 